\title{
Prevalence and Correlates of Complementary and Alternative Medicine Use among Patients with Lung Cancer: A Cross-Sectional Study in Beirut, Lebanon
}

\author{
Farah Naja, ${ }^{1}$ Bilal Anouti, ${ }^{2}$ Hibeh Shatila, ${ }^{1}$ Reem Akel, ${ }^{2}$ Yolla Haibe, $^{2}$ and Arafat Tfayli $^{2}$ \\ ${ }^{1}$ Department of Nutrition and Food Sciences, American University of Beirut, Riad El Solh, Beirut 1107 2020, Lebanon \\ ${ }^{2}$ Department of Internal Medicine, Division of Hematology/Oncology, American University of Beirut Medical Center, Riad El Solh, \\ Beirut 1107 2020, Lebanon
}

Correspondence should be addressed to Arafat Tfayli; at35@aub.edu.lb

Received 14 June 2017; Accepted 24 July 2017; Published 24 August 2017

Academic Editor: Mohammed S. Ali-Shtayeh

Copyright (C) 2017 Farah Naja et al. This is an open access article distributed under the Creative Commons Attribution License, which permits unrestricted use, distribution, and reproduction in any medium, provided the original work is properly cited.

\begin{abstract}
Patients with lung cancer are increasingly seeking complementary and alternative medicine (CAM) to improve their physiological and psychological well-being. This study aimed to assess CAM use among lung cancer patients in Lebanon. Using a cross-sectional design, 150 lung cancer patients attending the Basile Cancer Institute at the American University of Beirut Medical Center were interviewed. Participants completed a questionnaire addressing sociodemographic characteristics, lung cancer condition, and use of CAM. The main outcome of interest was "use of any CAM therapy since diagnosis." Prevalence of CAM use was $41 \%$. The most commonly used CAM modality among study participants was "dietary supplements/special foods." Results of the multiple logistic regression analyses showed that CAM use was positively associated with Lebanese nationality and paying for treatment out of pocket and was negatively associated with unemployment and having other chronic diseases. About 10\% of patients used CAM on an alternative base, $58 \%$ did not disclose CAM use to their physician, and only $2 \%$ cited health professionals as influencing their choice of CAM. This study revealed a prevalent CAM use among lung cancer patients in Lebanon, with a marginal role for physicians in guiding this use. Promoting an open-communication and a patient-centered approach regarding CAM use is warranted.
\end{abstract}

\section{Background}

Lung cancer is the most common cancer in the world, representing $12.7 \%$ of all new cancer cases [1]. The majority of these cases occur in less developed countries (55\%) [2]. Although lung cancer incidence rates and mortalities are still low in many countries of the Middle East and North Africa region (MENA) as compared to Europe or United States of American (USA), recent estimates are showing that these rates are gradually increasing in this region [3]. For instance, in Lebanon, among males, the prevalence of lung cancer was second to bladder cancer in 1986; however more recent data (in years 1992 and 2004) showed that lung cancer became the most prevalent malignancy $[4,5]$ with age-standardized incidence rates reaching 31.8 per 100,000 in 2008 [6]. In addition to its high prevalence in the world, lung cancer ranked first as the most common cause of cancer death, estimated to be responsible for one in five deaths (19.4\% of the total) [7]. Such a high mortality persisted despite the recent significant advances in medical treatment and management [8-10]. Possible explanations could be due to the fact that conventional treatments for lung cancer, including radiation, chemotherapy, and surgery, are all associated with significant side effects such as fatigue, cough, pain, difficulty breathing/breathlessness, loss of appetite, trouble sleeping, weight loss, nausea, difficulty concentrating, anxiety, and depression [11]. Individuals living with lung cancer experience a disproportionate higher number of symptoms compared with other types of cancer, possibly because their disease is more advanced at diagnosis [12].

The side effects associated with conventional treatments of lung cancer are of major concern for the patient and may lead to decreased compliance and adherence to treatment [13]. In addition, many patients in developing countries 
are diagnosed at an advanced stage of the disease where conventional therapy may be less efficient [14]. For these reasons, patients with lung cancer are increasingly seeking alternative forms of treatment $[13,15]$.

Complementary and alternative medicine (CAM) is defined as "diverse medical and health care systems, practices, and products that are not generally considered part of conventional medicine" [16]. It is classified in four main groups: mind-body medicine which increases the mind's ability to affect bodily function and symptoms (e.g., guided imagery), biologically based practices using substances found in nature (e.g., herbs), manipulative and body-based practices involving manipulation or movement of body parts (e.g., massage), and energy medicine involving use of energy fields (e.g., Reiki) [16].

CAM use is popular among all patient populations [17]. According to the WHO, over three-quarters of the globe's population has been reported to use a form of CAM for the purpose of treatment of chronic conditions [17]. A few studies suggested that cancer patients use more CAM than the general population $[18,19]$. In the USA, up to $90 \%$ of cancer patients used a form of CAM [20-23]. A cross-sectional survey of patients attending outpatient cancer clinics in Palestine reported a $69.5 \%$ prevalence of CAM use [24]. In Australia, recent studies reported that 30\%-65\% of cancer patients used CAM $[25,26]$. A similar rate was reported in Jordan, where a survey of cancer patients showed that the prevalence of CAM use was 35.5\% [27]. Concerning lung cancer patients, few studies have explored their use of CAM and the prevalence rates reported in the literature ranged between $4.3 \%$ in Greece [28] and 54\% in Germany [29]. The popular use of CAM in cancer patients presumably reflects the benefits, real or perceived, by those who use them [30]. Patients are either "pushed" towards CAM because of dissatisfaction with conventional medical treatment or "pulled" towards it because of their philosophical beliefs and values [31]. Specific reasons suggested to explain such a common use of CAM included patients wanting to take responsibility for their own health, to relieve symptoms, to promote health and increase healing [32], to increase hope and personal control, to seek closer provider relationships, and to improve physiologic and psychosocial well-being [33].

The popular use of CAM among cancer patients raises concerns regarding its safety and potential interaction with conventional treatment. While certain CAM modalities were found to have beneficial effects, others had deleterious consequences for health and well-being of patients. For instance, acupuncture and acupressure were shown to relieve chemotherapy-induced nausea and vomiting [34, 35]. In addition, acupuncture, hypnosis, therapeutic touch, and massage all led to a reduction in cancer-related pain [36, 37]. CAM use was also shown to contribute to an improvement in mental health and emotional well-being of cancer patients. For instance, yoga, meditation, and exercise were found to reduce stress in cancer patients $[18,38]$. On the other hand, the use of some forms of CAM among cancer patients could lead to unanticipated harm. Some CAM practices may worsen the side effects of conventional therapies and thus may negatively influence the compliance to conventional treatment [39].

One of the fastest growing markets of CAM products in the world has been documented to be within the MENA region [40]. In Lebanon, a small country of the MENA, this market is largely unregulated and could be subject to abuse by both patient and provider of CAM [41]. Given the high prevalence, burden, and mortality of lung cancer in Lebanon, obtaining information on the prevalence and correlates of CAM use among this patient population is important to influence physicians' priorities in advising their patients regarding the benefits and side effect of CAM use and help prioritize research investigating the efficacy and safety of CAM use. Therefore, the main aim of this study was to assess the prevalence and correlates of CAM use among patients diagnosed with lung cancer in Beirut, Lebanon. The specific objectives of the study were to assess the prevalence, characteristics, and determinants (demographic, sociocultural, economic, and medical) of CAM use among lung cancer patients as well as to examine the role of the physician in influencing CAM use in this patients' population.

\section{Methods}

2.1. Study Design and Participants. This was a cross-sectional survey assessing the prevalence and correlates of use of CAM among lung cancer patients attending the Naef K. Basile Cancer Institute at the American University of Beirut Medical Center [AUBMC]. Naef K. Basile Cancer Institute at AUBMC is the largest cancer center in the country with 2,500 new cancer patients evaluated each year, 13,000 hematology/oncology clinic visits, 14,000 patients treated at the ambulatory treatment unit, and 800 patients treated with radiation therapy. For this study, patients followed up in clinics at Naef K. Basile Cancer Institute were invited to participate. Inclusion criteria were patients older than 18 years of age, conversant in either the English or Arabic language, and diagnosed with lung cancer for at least 2 months. The 2-month duration would allow enough time for patients to explore the different CAM modalities. Patients were excluded if they were unable or unwilling to give consent for participation in the study. The study protocol has received ethical approval from the AUB IRB, under the protocol name IM.AT1.21. Sample size calculations showed that a total of 151 subjects were required in order to allow for an estimation of a $50 \%$ prevalence of CAM use at $95 \%$ confidence interval with an error margin not greater than $\pm 8 \%$.

2.2. Subject's Recruitment Protocol. Recruitment of patients took place at the clinics of Naef K. Basile Cancer Institute at AUBMC. Subjects meeting the inclusion criteria were briefed by the physician about the study. Subsequently, only patients who expressed willingness to participate were approached by the trained research fellow and were invited into an allocated private room in the clinic, where the consenting process and interview took place. IRB-approved consent forms were provided in English or Arabic based on the patient's preference. All of the research fellows/interviewers involved in this study 
had successfully completed the Collaborative Institutional Training Initiative (CITI) course as per the requirements of the Institutional Review Board (IRB). The research fellows assured the patients that confidentiality was highly respected and any information collected will not be shared with their health care providers.

2.3. Survey Instrument. In a face-to-face interview with the research fellow, participants completed a multicomponent questionnaire. The questionnaire was comprised of three sections: the first section includes questions assessing sociodemographic characteristics of the study participants such as age, gender, nationality, marital status, educational level, employment status, type of health insurance, and household income. The second section included questions specific to their lung cancer diagnosis, such as the duration of cancer, current state of the cancer, family history of lung cancer, and presence of other chronic diseases such as cardiovascular diseases (CVD) or chronic obstructive pulmonary diseases (COPD). The last section of the questionnaire included questions assessing the type of CAM treatments used, their mode of use (as complementary or alternative to conventional medical treatment and their frequency of use), their cost, perceived side effects, reasons of use, disclosure of CAM use to the physician, his/her reaction to its use, and what the main factors influencing the choice of CAM were. The content validity of this questionnaire was confirmed by a panel of experts consisting of one physician, one nutrition epidemiologist, and one health policy expert. The questionnaire was originally written in English, was translated to the Arabic language, and then back translated to English. The original and back-translated English versions of the questionnaire were examined to ensure parallel form reliability.

2.4. Data Analysis. The main outcome of this study was to determine the prevalence of CAM use among lung cancer patients. Patients were classified as users or nonusers of CAM based on whether they have used any form of CAM since diagnosis or not.

Proportions were used to describe the correlates and characteristics of CAM use. The two groups (users and nonusers of CAM) were compared using a Chi-square analysis. The associations of various sociodemographic and disease characteristics with CAM use were examined using simple logistic regression analyses. The dependent variable in these regression analyses was the use of CAM. In order to adjust for possible confounders and evaluate independent effects of each variable on the outcome (CAM use), a multiple regression model was built, in which all sociodemographic and disease characteristics were used as independent variables. Statistical significance was set at a $p$ value $<0.05$. Statistical Package for Social Sciences (SPSS) software version 20.0 for windows program was utilized to analyze the data.

\section{Results}

Data collection took place over the course of one year, between September 2015 and August 2016. Out of 156 lung cancer patients invited, 150 agreed to participate and completed the questionnaire (response rate: $96 \%$ ). The prevalence of CAM use after diagnosis with lung cancer among the study participants was found to be $41 \%$.

Table 1 displayed the various characteristics of the study population and their association with CAM use. The majority of participants were males (71\%), married (89\%), and had some form of health insurance $(72 \%)$. Out of each four patients, three were Lebanese. Other nationalities reported were Iraqi (20\%) and Syrian (7\%). Only 35\% of participants were employed at the time of the interview. As for the characteristics of the cancer, $38 \%$ of patients reported being diagnosed with the disease for more than one year and $24 \%$ between 2 and 3 months. Almost half of the participants had a metastatic cancer (52\%) and $24 \%$ had a family history of lung cancer. Of study participants, $45 \%$ suffered from additional diseases such as hypertension, CVD, or COPD (Table 1). Using Chi-square test, "age," "employment status," and "suffering from other diseases" were shown to be significantly associated with CAM use (Table 1). Specifically, a higher percentage of CAM users was noted among patients younger than 55 years as compared to those who are older (60\% versus $37 \%)$. The highest proportion of CAM users was found among employed patients (52\%), as compared to retired $(40 \%)$ and unemployed $(33 \%)$. The prevalence of CAM use was higher among patients with lung cancer compared to that among patients suffering from additional diseases (53\% versus $27 \%$ ).

These findings were confirmed by the results of the simple logistic regression, displayed in Table 2, whereby the factors significantly associated with higher prevalence of CAM use were an older age, employment, and not suffering from other diseases. More specifically, the results of this study revealed lower odds of CAM use in association with age $>55$ years (OR: $0.39,95 \%$ CI $0.17-0.87$ ), being unemployed (OR: 0.44 , 95\% CI 0.19-0.98), and suffering from other diseases (OR: $0.34,95 \%$ CI $0.17-0.68)$. The multiple logistic regression model used to examine the correlates of CAM use after adjustment showed that CAM use increased significantly among Lebanese patients compared to non-Lebanese (OR: 7.9, 95\% CI 1.13-55.45) and among subjects paying out of pocket for the treatment of lung cancer (OR: 13.54, 95\% CI 2.23-82.23). Similar to the findings of the simple regression, the multiple regression analysis also showed that CAM use was associated with employment and not suffering from other diseases [unemployed (OR: 0.19, 95\% CI 0.034-0.89); suffering from other diseases (OR: 0.13, 95\% CI 0.03-0.52)]. The multiple regression model had a Chi-square value of 28.80 with a $p$ value of 0.01 .

The different types of CAM used among the study population were illustrated in Figure 1. The most commonly used CAM was "dietary supplements (special foods)," followed by "herbal remedies," "vitamin/mineral supplements," "spiritual healing," and "cannabis/marijuana." The "dietary supplements (special foods)" category included graviola seeds, helia mushroom and milk, quinoa seeds and avocado mix, and cherimoya. "Herbal remedies" consisted of different kind of herbs such as Shita (herb found mainly in Morocco), thyme, lou'loub, spices, A'landa (from Palestine), and herbal 
TABLE 1: Sociodemographic and disease-related characteristics of study participants by CAM use $(n=150)^{*}$.

\begin{tabular}{|c|c|c|c|c|}
\hline Characteristics & $\begin{array}{l}\text { Overall } \\
n=150\end{array}$ & $\begin{array}{c}\text { CAM users } \\
n=62\end{array}$ & $\begin{array}{c}\text { CAM nonusers } \\
n=88\end{array}$ & $p$ value $^{* *}$ \\
\hline \multicolumn{5}{|l|}{ Age (years) } \\
\hline$\leq 55$ years & $30(20)$ & $18(60)$ & $12(40)$ & \multirow[t]{2}{*}{0.02} \\
\hline$>55$ years & $120(80)$ & $44(37)$ & $76(63)$ & \\
\hline \multicolumn{5}{|l|}{ Gender } \\
\hline Male & $106(71)$ & $44(42)$ & $62(59)$ & \multirow{2}{*}{0.54} \\
\hline Female & $44(29)$ & $18(41)$ & $26(59)$ & \\
\hline \multicolumn{5}{|l|}{ Nationality } \\
\hline Non-Lebanese & $37(25)$ & $13(35)$ & $24(65)$ & \multirow{2}{*}{0.25} \\
\hline Lebanese & $113(75)$ & $49(43)$ & $64(57)$ & \\
\hline \multicolumn{5}{|l|}{ Marital status } \\
\hline Single & $16(11)$ & $4(25)$ & $12(75)$ & \multirow{2}{*}{0.13} \\
\hline Married/live in & $134(89)$ & $58(43)$ & $79(59)$ & \\
\hline \multicolumn{5}{|l|}{ Educational level } \\
\hline High school level & $89(59)$ & $34(38)$ & $55(62)$ & \multirow[t]{2}{*}{0.22} \\
\hline University level & $61(41)$ & $28(46)$ & $33(54)$ & \\
\hline \multicolumn{5}{|l|}{ Employment status ${ }^{* * *}$} \\
\hline Employed & $52(35)$ & $27(52)$ & $25(48)$ & \multirow{3}{*}{0.05} \\
\hline Retired & $47(32)$ & $19(40)$ & $28(60)$ & \\
\hline Unemployed & $49(33)$ & $16(33)$ & $33(67)$ & \\
\hline \multicolumn{5}{|l|}{ Type of health insurance } \\
\hline Insured (public/private) & $108(72)$ & $41(38)$ & $67(62)$ & \multirow{2}{*}{0.12} \\
\hline Self-paying & $42(28)$ & $21(34)$ & $21(24)$ & \\
\hline \multicolumn{5}{|c|}{ Monthly household income $e^{* * *}$} \\
\hline$<1000 \$$ & $55(41)$ & $20(36)$ & $35(64)$ & \multirow{2}{*}{0.11} \\
\hline$\geq 1000 \$$ & $78(59)$ & $38(49)$ & $40(51)$ & \\
\hline \multicolumn{5}{|c|}{ Disease-related characteristics } \\
\hline \multicolumn{5}{|l|}{ Duration of lung cancer } \\
\hline 2-3 months & $36(24)$ & $16(44)$ & $20(56)$ & \multirow{3}{*}{0.56} \\
\hline 4-12 months & $57(38)$ & $24(42)$ & $33(58)$ & \\
\hline$>1$ year & $57(38)$ & $22(39)$ & $35(61)$ & \\
\hline \multicolumn{5}{|c|}{ Current status of lung cancer ${ }^{* * *}$} \\
\hline Early/locally advanced & $46(48)$ & $19(41)$ & $27(59)$ & \multirow{2}{*}{0.55} \\
\hline Metastatic & $49(52)$ & $21(43)$ & $28(57)$ & \\
\hline \multicolumn{5}{|c|}{ Family history of lung cancer ${ }^{* * *}$} \\
\hline No & $110(76)$ & $45(41)$ & $65(59)$ & \multirow{2}{*}{0.45} \\
\hline Yes & $34(24)$ & $15(2544)$ & $19(56)$ & \\
\hline \multicolumn{5}{|c|}{ Suffer from other diseases (hypertension or CVD or COPD) ${ }^{* * *}$} \\
\hline No & $80(55)$ & $42(53)$ & $38(48)$ & \multirow{2}{*}{$<0.01$} \\
\hline Yes & $66(45)$ & $18(27)$ & $48(73)$ & \\
\hline
\end{tabular}

${ }^{*}$ Values in this table represent $n(\%) ;{ }^{* *} p$ values were derived from Chi-square tests; ${ }^{* * *}$ missing data (the totals of these variables do not add up to 150$)$.

teas. "Spiritual healing" category included various forms of prayers, visiting sanctuaries, seeking the blessing of various religious figures, and drinking "Zamzam water." The latter is a type of holy water Muslims bring from Mecca.

Table 3 described the characteristics of CAM use among study participants. Almost $10 \%$ of patients indicated using
CAM as alternative to conventional treatments and more than half reported not asking their doctor about use of CAM (58\%). Among patients who asked the doctor, $46 \%$ said that the doctors' reaction to CAM use was encouraging while $19 \%$ said it was not. The two most common reasons reported for not disclosing CAM use to treating physicians were "not 
TABLE 2: Correlates of CAM use among study participants using simple and multiple logistic regression analyses $(n=150)^{*, * *}$.

\begin{tabular}{|c|c|c|}
\hline & Univariate logistic regression & Multiple logistic regression \\
\hline \multicolumn{3}{|l|}{ Age (years) } \\
\hline$\leq 55$ years & 1 & 1 \\
\hline$>55$ Years & $0.39(0.17-0.87)$ & $0.61(0.13-2.79)$ \\
\hline \multicolumn{3}{|l|}{ Gender } \\
\hline Male & 1 & 1 \\
\hline Female & $1.02(0.50-2.09)$ & $2.07(0.46-9.20)$ \\
\hline \multicolumn{3}{|l|}{ Nationality } \\
\hline Non-Lebanese & 1 & 1 \\
\hline Lebanese & $1.41(0.65-3.05)$ & $7.9(1.13-55.45)$ \\
\hline \multicolumn{3}{|l|}{ Marital status } \\
\hline Single & 1 & 1 \\
\hline Married/live in & $2.13(0.65-6.94)$ & $6.20(0.31-125.49)$ \\
\hline \multicolumn{3}{|l|}{ Educational level } \\
\hline High school level & 1 & 1 \\
\hline University level & $1.37(0.71-2.66)$ & $0.67(0.17-2.67)$ \\
\hline \multicolumn{3}{|l|}{ Employment status } \\
\hline Employed & 1 & 1 \\
\hline Retired & $0.63(0.28-1.37)$ & $0.82(0.21-3.24)$ \\
\hline Unemployed & $0.44(0.19-0.98)$ & $0.19(0.034-0.89)$ \\
\hline \multicolumn{3}{|l|}{ Type of health insurance } \\
\hline Insured (public/private) & 1 & 1 \\
\hline Self-paying & $1.64(0.80-3.35)$ & $13.54(2.23-82.23)$ \\
\hline \multicolumn{3}{|l|}{ Monthly Income } \\
\hline$<1000$ & 1 & 1 \\
\hline$>1000$ & $1.66(0.82-3.37)$ & $2.57(0.66-10.02)$ \\
\hline \multicolumn{3}{|c|}{ Duration of lung cancer $(n=76)$} \\
\hline $2-3$ months & 1 & 1 \\
\hline 4-12 months & $0.91(0.39-2.11)$ & $1.20(0.22-6.42)$ \\
\hline$>1$ year & $0.79(0.33-1.83)$ & $0.39(0.08-1.74)$ \\
\hline \multicolumn{3}{|l|}{ Current status of lung cancer } \\
\hline Early/locally advanced & 1 & 1 \\
\hline Metastatic & $1.07(0.47-2.41)$ & $0.95(0.28-3.20)$ \\
\hline \multicolumn{3}{|l|}{ Family history of lung cancer } \\
\hline No & 1 & 1 \\
\hline Yes & $1.14(0.52-2.48)$ & $0.35(0.07-1.62)$ \\
\hline \multicolumn{3}{|c|}{ Suffer from other diseases (hypertension or CVD or COPD) } \\
\hline No & 1 & 1 \\
\hline Yes & $0.34(0.17-0.68)$ & $0.13(0.03-0.52)$ \\
\hline
\end{tabular}

${ }^{*}$ Values in this table represent odds ratios (OR) and their corresponding $95 \%$ confidence intervals (CI). ${ }^{* *}$ Significant OR and their corresponding $95 \% \mathrm{CI}$ are bolded.

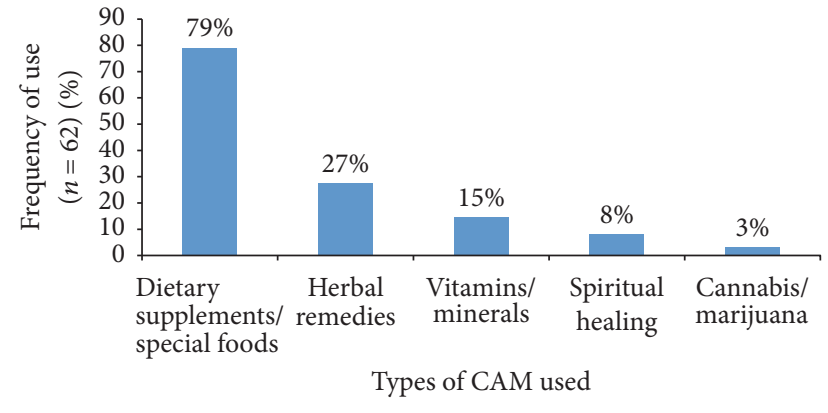

FIGURE 1: Types of CAM used in the study population $(n=62)$. important, does not affect health" (47\%) followed by "though it's important, I did not have the chance/time" (32\%). When asked about the main influence of CAM choice, participants indicated friends (48\%), media (40\%), and personal choice (19\%). Health practitioners were among the least to influence patients' choice of CAM (2\%). The majority of CAM users (92\%) reported experiencing no side effects associated with their use of CAM and $78 \%$ indicated that they would use CAM again.

When non-CAM users were asked if they would consider using CAM in the future, $70 \%$ said they would not. The main 
TABLE 3: Prevalence and characteristics of CAM use in the study population $(n=150)$.

\begin{tabular}{|c|c|}
\hline Prevalence of CAM use & $n(\%)$ \\
\hline \multicolumn{2}{|l|}{ Used CAM in the previous year } \\
\hline No & $107(71)$ \\
\hline Yes & $43(29)$ \\
\hline \multicolumn{2}{|l|}{ Used CAM since diagnosis } \\
\hline No & $88(59)$ \\
\hline Yes & $62(41)$ \\
\hline \multicolumn{2}{|l|}{ CAM related characteristics among CAM users $(n=62)$} \\
\hline \multicolumn{2}{|l|}{ Alternative or complementary to conventional treatment } \\
\hline Complementary & $56(90)$ \\
\hline Alternative & $6(10)$ \\
\hline \multicolumn{2}{|l|}{ Asked doctor about CAM used } \\
\hline No & $36(58)$ \\
\hline Yes & $26(42)$ \\
\hline \multicolumn{2}{|l|}{ Doctor's reaction to CAM use $(n=26)$} \\
\hline Neutral & $9(35)$ \\
\hline Encouraging & $12(46)$ \\
\hline Discouraging & $5(19)$ \\
\hline \multicolumn{2}{|l|}{ Reasons for not disclosing CAM use to doctors $(n=19)$} \\
\hline Not important, does not affect health & $9(47)$ \\
\hline Though important, I did not have the chance/time & $6(32)$ \\
\hline Doctors does not believe in it & $2(11)$ \\
\hline Doctors does not have the expertise & $1(5)$ \\
\hline Doctor will be angry & $1(5)$ \\
\hline \multicolumn{2}{|l|}{ CAM choice* } \\
\hline Friends & $30(48)$ \\
\hline Media & $25(40)$ \\
\hline Personal choice & $12(19)$ \\
\hline Family beliefs & $8(13)$ \\
\hline Health food shop & $2(3)$ \\
\hline Alternative medicine therapist & $2(3)$ \\
\hline Health practitioner & $1(2)$ \\
\hline Religious beliefs & $1(2)$ \\
\hline \multicolumn{2}{|l|}{ Frequency of CAM use } \\
\hline Only one time & $7(11)$ \\
\hline Once per month & $3(5)$ \\
\hline Regular (at least twice a week for a minimum of one month) & $46(74)$ \\
\hline Other & $6(10)$ \\
\hline \multicolumn{2}{|l|}{ CAM provider } \\
\hline Purchased from local store/pharmacy & $44(76)$ \\
\hline Naturopath & $8(14)$ \\
\hline Practitioner of traditional medicine & $2(3)$ \\
\hline Homeopath & $2(3)$ \\
\hline Massage therapist & $1(2)$ \\
\hline Secret dealer (cannabis/marijuana) & $1(2)$ \\
\hline \multicolumn{2}{|l|}{ Estimated cost of CAM use per month } \\
\hline$<10 \$$ & $16(29)$ \\
\hline $10-50 \$$ & $16(29)$ \\
\hline$>50 \$$ & $23(42)$ \\
\hline \multicolumn{2}{|l|}{ Reasons for CAM use* } \\
\hline To improve general health and ensure long term survival & $35(57)$ \\
\hline To manage cancer complications/progression & $32(52)$ \\
\hline Belief in advantages of CAM & $27(44)$ \\
\hline
\end{tabular}


TABLE 3: Continued.

\begin{tabular}{|c|c|}
\hline Prevalence of CAM use & $n(\%)$ \\
\hline To help in relaxation and feeling better psychologically & $25(40)$ \\
\hline More natural practice & $25(40)$ \\
\hline To reduce side effects of conventional therapy & $24(39)$ \\
\hline To feel more in control over health & $20(32)$ \\
\hline Curiosity & $10(16)$ \\
\hline To provide energy & $9(15)$ \\
\hline Family tradition/culture & $9(15)$ \\
\hline Religious & $4(7)$ \\
\hline \multicolumn{2}{|l|}{ How do you assess the usefulness of CAM? } \\
\hline Not at all & $14(23)$ \\
\hline Some & $9(15)$ \\
\hline A lot, very satisfied & $17(27)$ \\
\hline Can’t tell & $22(36)$ \\
\hline \multicolumn{2}{|l|}{ Side effects from CAM $(n=60)$} \\
\hline No & $55(92)$ \\
\hline Yes & $2(3)$ \\
\hline Undecided & $3(5)$ \\
\hline \multicolumn{2}{|l|}{ Would you use CAM again? $(n=60)$} \\
\hline No & $9(15)$ \\
\hline Yes & $47(78)$ \\
\hline Undecided & $4(8)$ \\
\hline \multicolumn{2}{|l|}{ Would you recommend CAM use to other lung cancer patients? } \\
\hline No & $13(21)$ \\
\hline Yes & $40(65)$ \\
\hline Undecided & $9(15)$ \\
\hline
\end{tabular}

${ }^{*}$ Several answers apply.

reasons for not using CAM were "lack of belief in the benefits of CAM" (61\%) and the fact that the doctor did not prescribe it $(33 \%)$.

\section{Discussion}

This cross-sectional study investigated the use and perception of CAM among lung cancer patients living in Beirut, Lebanon. The prevalence of CAM use among patients with lung cancer found in this study (41\%) was comparable to estimates by previous reports. For instance, in a study examining CAM use among patients with lung cancer in European countries, prevalence rates were found to be $33.3 \%$ in Turkey, 37.2\% in Spain, 40\% in Denmark, and $42.9 \%$ in Israel [28]. In addition, in a study assessing CAM use among women with lung cancer in different institutions in the USA, $45 \%$ of patients reported using CAM [42]. However, lower prevalence rate was also reported in the literature, such as $25 \%$ in Sweden, $16.7 \%$ in Switzerland, $12.5 \%$ in UK, and as low as $4.3 \%$ in Greece [28]. On the contrary, relatively higher rates of CAM use were reported among lung cancer patients in Pennsylvania, USA, and Germany (50.9\% and 54\%, resp.) $[29,43]$. Possible reasons for the variation in the prevalence of CAM use observed among different countries and geographical locations may be explained partly by differences in sociocultural perception of CAM use and disparities in the availability and access to conventional medicine. Moreover, differences in study design and definitions of what could be constituting CAM might have also contributed to the variation observed in prevalence of CAM use among lung cancer patients across countries [44]. It is important to note that the prevalence of CAM use among lung cancer patients found in this study was similar to that previously observed among a sample of breast cancer patients in Lebanon (40\%) [45]. These prevalence rates (among lung and breast cancer patients) were higher than the prevalence of CAM use in the general population in Lebanon, estimated at the national level (29.87\%) [46]. Such findings supported results of previous studies indicating that patients with chronic diseases are more likely to resort to CAM use compared to the general population $[47,48]$.

Similar to previous reports, findings of this study suggested that unemployment was associated with lower odds of CAM use $[45,49]$. In addition, in this study, patients paying out of pocket for the cancer treatment were more likely to use CAM, as compared to those relying on a form of health insurance. In the Lebanese context, these findings suggested that CAM use among lung cancer patients followed a socioeconomic gradient whereby patients with a higher socioeconomic status (employed and paying out of pocket for their treatment) were more likely to use CAM. Such an association between a higher socioeconomic status and 
CAM use could be a reflection of the fact that, in Lebanon, CAM products and therapies are paid by the patient and not covered by available medical insurance policies [41]. In fact, in this study, more than $40 \%$ of patients indicated spending over 50 USD on CAM per month. For these patients, considering the GDP per capita estimated in Lebanon (8050 USD), the amount spent on CAM constituted a significant proportion (7.5\%) [50].

In this study, patients with a Lebanese nationality were found to be more likely to use CAM than non-Lebanese patients, who were mainly Iraqis and Syrians. It could be argued that since the use of CAM in this study was found to be mainly influenced by friends and media as well as family beliefs, patients who are not Lebanese and are staying in Lebanon might be possibly away from their families and friends and hence were less influenced to use CAM. Furthermore, most of non-Lebanese patients come to Lebanon in order to receive conventional medical care offered at Naef $\mathrm{K}$. Basile Cancer Institute at AUBMC and therefore may be more likely to report lower odds of CAM use compared to their Lebanese counterparts.

In congruence with earlier reports, in this study, the most common forms of CAM used by lung cancer patients were found to be dietary supplements/special foods and herbal remedies and vitamin/minerals [28, 43-45]. The high prevalence of use of these types of herbal CAM reflected the Lebanese and Arab ancient heritage that used the rich flora and herbal diversity of the region to create remedies for treating and curing diseases [51, 52]. The prevalent use of these CAM modalities could also be due to the general perception that they are natural and will not be harmful or have any side effects [45]. Patients tend not to be aware that many of the herbal preparations may contain dilute scores of different chemicals, the effects of most of which on cancer have not been documented [53]. In fact, some herbs may cause problematic interactions with chemotherapeutic agents, sensitization of the skin to radiation therapy, dangerous blood pressure swings, and other unwanted interactions with anesthetics during surgery [54].

In this study, $10 \%$ of patients reported using CAM as an alternative treatment. While this proportion remains alarming, it is important to note that it may be in fact an underestimation of the actual percentage of patients who may use CAM on alternative basis given that data was collected in a hospital setting, where patients were coming to receive a form of conventional treatment and would have been reluctant to report using CAM as alternative treatment. From a patient care perspective, this could cause delays in the start of and adherence to conventional cancer treatments [55]. Therefore, despite the low prevalence of alternative use of CAM therapies observed in the study, the repercussions could be significant with potential negative consequences on patients, their families, and the health system at large (increased cost of treatment). Among the factors reported to affect the decision of patients to resort to CAM use and decline conventional treatment were dissatisfaction with conventional medical practices [56], poor doctor-patient communication, frustration with the contradictory and consistently evolving state of current medical knowledge $[57,58]$, the increasing cost of conventional medical care [59], the intellectual and spiritual appeal of holistic models of health and healing [60], and the need for a sense of control over own health and self-management of the cancer [61].

In line with findings of previous studies examining the use of CAM among cancer patients, this study showed that $58 \%$ of patients did not disclose CAM usage to their treating physicians $[42,62]$. When asked about the main reasons for not disclosing, patients in this study reported that CAM use does not need to be discussed with the physician. Furthermore, even when the patients wanted to discuss CAM use with the physicians they did not seem to have the time. The marginal role of the physician suggested by the findings of this study was further underscored by the fact that the majority of patients using CAM chose their CAM based on input from friends (48\%) and media (40\%) and only $1 \%$ relied on health practitioners. This is in accordance with the results of previous studies examining CAM use among various patient populations in Lebanon, including breast cancer, Type 2 Diabetes Mellitus, and infertility as well as pediatric leukemia [63]. The study on CAM use among lung cancer patients in different European countries also showed similar findings, where the most prominent sources of information for CAM choice were outside the medical system and included friends (65.4\%), followed by family (30.8\%) and media (23.1\%) [28].

The findings of this study regarding a marginal role of the physician in the patients' choice of CAM use raise concerns regarding the physician-patient communication. The latter is increasingly considered as integral and an important part of cancer treatment [64], as it may protect patients from possible harmful effect of certain CAM therapies and improve adherence to recommended conventional treatment [65]. Mutuality and shared decision making between physicians and cancer patients could address the need of patients to have an active role in the treatment decisions and processes and hence may adhere better to the recommended treatment. Previous research suggested that the use of a simple screening question may allow patients who wish to discuss CAM to have the opportunity to disclose information and seek advice from their treating physicians [66]. It could be argued that physicians may feel uncomfortable receiving questions about CAM from their patients given their limited knowledge about the subject. In fact, a study of knowledge about CAM among registered health care providers in Sweden showed that communication between patient and health care provider regarding CAM was rare and that over $90 \%$ of participants had minor or no knowledge about CAM [67]. Therefore, integration of CAM modules in undergraduate and graduate medical education may help alleviate physicians' discomfort related to answering questions about CAM and enhance patient-physician communication regarding CAM use [68].

The findings of this study ought to be considered in light of a few limitations. First, the selection of one medical center might have affected the generalizability of the findings. However, the Naef K. Basile Cancer Institute at AUBMC is considered the largest cancer treating center in Lebanon (as evidenced by the high patient load) and is a major referral center for the treatment of all cancers from Lebanon 
and the region. Second, it is possible to conceive that the prevalence estimate of CAM use obtained in this study may be an underestimation of the actual prevalence since patients' recruitment took place in a clinical setting and hence they may have been biased towards conventional medicine use. In addition, the interviewer-based approach in data collection could have resulted in a social desirability bias; however research fellows were extensively trained to have a nonjudgmental and neutral attitude and used standardized techniques, avoiding questions that could influence the subject's responses [69].

\section{Conclusion}

This is the first study in the MENA region and Lebanon to examine the use of CAM among lung cancer patients. Findings of this study highlighted a prevalent use of CAM among lung cancer patients in Lebanon, with dietary supplements/special foods and herbal remedies, and vita$\mathrm{min} /$ minerals being the most commonly used CAM modality. While older patients and those belonging to a lower socioeconomic status were less likely to use CAM, patients paying out of pocket for treatment or holders of the Lebanese nationality were more likely to use some form of CAM. Furthermore, the results of this study suggested a marginal role of the treating physicians played in orienting CAM use since the majority of the patients were found to rely on friends and media for choice of CAM and a significant proportion of patients did not disclose their CAM use to their physicians. The findings of this study revealed the need for a concerted effort to improve patient-physician communication and heighten awareness of both practitioners and patients with lung cancer on the proper and safe use of CAM therapies in adjunction with conventional treatment modalities.

\section{Conflicts of Interest}

The authors declare that there are no conflicts of interest regarding the publication of this article.

\section{Acknowledgments}

The authors would like to express their gratitude to all study participants who took the time to complete the questionnaires.

\section{References}

[1] J. Ferlay, H. R. Shin, F. Bray, D. Forman, C. Mathers, and D. M. Parkin, "Estimates of worldwide burden of cancer in 2008: GLOBOCAN 2008," International Journal of Cancer, vol. 127, no. 12, pp. 2893-2917, 2010.

[2] WHO, GlOBOCAN 2012: Estimated Cancer Incidence, Mortality abd Prevalence Worldwide in 2012, "http://globocan.iarc.fr/ Pages/fact_sheets_cancer.aspx.

[3] E. I. Salim, A. R. Jazieh, and M. A. Moore, "Lung cancer incidence in the Arab league countries: risk factors and control,"
Asian Pacific Journal of Cancer Prevention, vol. 12, no. 1, pp. 1734, 2011.

[4] N. S. El Saghir, "An update on recent cancer trends in Lebanon," Ethnicity and Disease, pp. 11-17, 2005.

[5] A. I. Shamseddine and K. M. Musallam, "Cancer epidemiology in Lebanon," Middle East Journal of Cancer, vol. 1, no. 1, pp. 4144, 2010.

[6] A. Shamseddine, A. Saleh, M. Charafeddine et al., "Cancer trends in Lebanon: a review of incidence rates for the period of 2003-2008 and projections until 2018," Population Health Metrics, vol. 12, no. 1, article no. 4, 2014.

[7] WHO, "Fact sheet : Cancer,“ 2017, http://www.who.int/mediacentre/factsheets/fs297/en/.

[8] S. Novello, F. Barlesi, R. Califano et al., "Metastatic nonsmall-cell lung cancer: ESMO Clinical Practice Guidelines for diagnosis, treatment and follow-up," Annals of Oncology, vol. 27, pp. V1-V27, 2016.

[9] C. C. Society, ”Lung Cancer Statistics, “2016, http://www.cancer .ca/en/cancer-information/cancer-type/lung/statistics/?region= on.

[10] C. R. UK, "Lung Cancer Statistics," 2016, http://www.cancerresearchuk.org/health-professional/cancer-statistics/statistics-bycancer-type/lung-cancer\#heading-Two.

[11] J. Potter and I. J. Higginson, "Pain experienced by lung cancer patients: a review of prevalence, causes and pathophysiology," Lung Cancer, vol. 43, no. 3, pp. 247-257, 2004.

[12] K. Carlsen, A. B. Jensen, E. Jacobsen, M. Krasnik, and C. Johansen, "Psychosocial aspects of lung cancer," Lung Cancer, vol. 47, no. 3, pp. 293-300, 2005.

[13] P. Fox, M. Butler, B. Coughlan et al., "Using a mixed methods research design to investigate complementary alternative medicine (CAM) use among women with breast cancer in Ireland," European Journal of Oncology Nursing, vol. 17, no. 4, pp. 490-497, 2013.

[14] Z. Chen, K. Gu, Y. Zheng, W. Zheng, W. Lu, and X. O. Shu, "The use of complementary and alternative medicine among Chinese women with breast cancer," The Journal of Alternative and Complementary Medicine, vol. 14, no. 8, pp. 1049-1055, 2008.

[15] A. Molassiotis, P. Fernandez-Ortega, D. Pud et al., "Use of complementary and alternative medicine in cancer patients: a European survey," Annals of Oncology, vol. 16, no. 4, pp. 655663, 2005.

[16] National Center for Complimentary and Integrative Health, "The Use of Complementary and Alternative Medicine in the United States," 2016, https://nccih.nih.gov/research/statistics/ 2007/camsurvey_fs1.htm\#use.

[17] T. Edirne, S. G. Arica, S. Gucuk et al., "Use of complementary and alternative medicines by a sample of Turkish women for infertility enhancement: a descriptive study," BMC Complementary and Alternative Medicine, vol. 10, article 11, 2010.

[18] A. B. Moadel, C. Shah, J. Wylie-Rosett et al., "Randomized controlled trial of yoga among a multiethnic sample of breast cancer patients: effects on quality of life," Journal of Clinical Oncology, vol. 25, no. 28, pp. 4387-4395, 2007.

[19] National Center for Complementary and Integrative Health, "Cancer: In Depth," 2016, https://nccih.nih.gov/health/cancer/ complementary-integrative-research.

[20] J. S. Yates, K. M. Mustian, G. R. Morrow et al., "Prevalence of complementary and alternative medicine use in cancer patients during treatment," Supportive Care in Cancer, vol. 13, no. 10, pp. 806-811, 2005. 
[21] M. A. Richardson, T. Sanders, J. L. Palmer, A. Greisinger, and S. E. Singletary, "Complementary/alternative medicine use in a comprehensive cancer center and the implications for oncology," Journal of Clinical Oncology, vol. 18, no. 13, pp. 25052514, 2000.

[22] S. M. Rausch, F. Winegardner, K. M. Kruk et al., "Complementary and alternative medicine: use and disclosure in radiation oncology community practice," Supportive Care in Cancer, vol. 19, no. 4, pp. 521-529, 2011.

[23] J. M. Fouladbakhsh, M. Stommel, B. A. Given, and C. W. Given, "Predictors of use of complementary and alternative therapies among patients with cancer," Oncology Nursing Forum, vol. 32, no. 6, pp. 1115-1122, 2005.

[24] M. S. Ali-Shtayeh, R. M. Jamous, N. M. Y. Salameh, R. M. Jamous, and A. M. A. Hamadeh, "Complementary and alternative medicine use among cancer patients in Palestine with special reference to safety-related concerns," Journal of Ethnopharmacology, vol. 187, pp. 104-122, 2016.

[25] C. Pirri, P. Katris, J. Trotter, E. Bayliss, R. Bennett, and P. Drummond, "Use of complementary and alternative therapies by Western Australian cancer patients," Asia-Pacific Journal of Clinical Oncology, vol. 4, no. 3, pp. 161-169, 2008.

[26] B. Oh, P. Butow, B. Mullan et al., "The use and perceived benefits resulting from the use of complementary and alternative medicine by cancer patients in Australia," Asia-Pacific Journal of Clinical Oncology, vol. 6, no. 4, pp. 342-349, 2010.

[27] F. U. Afifi, M. Wazaify, M. Jabr, and E. Treish, "The use of herbal preparations as complementary and alternative medicine (CAM) in a sample of patients with cancer in Jordan," Complementary Therapies in Clinical Practice, vol. 16, no. 4, pp. 208-212, 2010.

[28] A. Molassiotis, V. Panteli, E. Patiraki et al., "Complementary and alternative medicine use in lung cancer patients in eight European countries," Complementary Therapies in Clinical Practice, vol. 12, no. 1, pp. 34-39, 2006.

[29] O. Micke, J. Büntzel, K. Kisters, U. Schäfer, P. Micke, and R. Mücke, "Complementary and alternative medicine in lung cancer patients: a neglected phenomenon?" Frontiers of Radiation Therapy and Oncology, vol. 42, pp. 198-205, 2010.

[30] N. Klafke, J. A. Eliott, G. A. Wittert, and I. N. Olver, "Prevalence and predictors of complementary and alternative medicine (CAM) use by men in Australian cancer outpatient services," Annals of Oncology, vol. 23, no. 6, pp. 1571-1578, 2012.

[31] A. Furnham and C. Smith, "Choosing alternative medicine: a comparison of the beliefs of patients visiting a general practitioner and a homoeopath," Social Science and Medicine, vol. 26, no. 7, pp. 685-689, 1988.

[32] S. Thorne, B. Paterson, C. Russell, and A. Schultz, "Complementary/alternative medicine in chronic illness as informed selfcare decision making," International Journal of Nursing Studies, vol. 39, no. 7, pp. 671-683, 2002.

[33] B. R. Cassileth, G. E. Deng, J. E. Gomez, P. A. S. Johnstone, N. Kumar, and A. J. Vickers, "Complementary therapies and integrative oncology in lung cancer: ACCP evidence-based clinical practice guidelines," CHEST Journal, vol. 132, no. 3, pp. 340S-354S, 2007.

[34] J. Klein and P. Griffiths, "Acupressure for nausea and vomiting in cancer patients receiving chemotherapy," British Journal of Community Nursing, vol. 9, no. 9, pp. 383-387, 2004.

[35] T. Bao, "Use of acupuncture in the control of chemotherapyinduced nausea and vomiting," Journal of the National Comprehensive Cancer Network, vol. 7, no. 5, pp. 606-612, 2009.
[36] C. X. Pan, R. S. Morrison, J. Ness, A. Fugh-Berman, and R. M. Leipzig, "Complementary and alternative medicine in the management of pain, dyspnea, and nausea and vomiting near the end of Life: a systematic review," Journal of Pain and Symptom Management, vol. 20, no. 5, pp. 374-387, 2000.

[37] A. Bardia, D. L. Barton, L. J. Prokop, B. A. Bauer, and T. J. Moynihan, "Efficacy of complementary and alternative medicine therapies in relieving cancer pain: a systematic review," Journal of Clinical Oncology, vol. 24, no. 34, pp. 5457-5464, 2006.

[38] V. S. Conn, A. R. Hafdahl, D. C. Porock, R. McDaniel, and P. J. Nielsen, "A meta-analysis of exercise interventions among people treated for cancer," Supportive Care in Cancer, vol. 14, no. 7, pp. 699-712, 2006.

[39] J. Yarney, A. Donkor, S. Y. Opoku et al., "Characteristics of users and implications for the use of complementary and alternative medicine in Ghanaian cancer patients undergoing radiotherapy and chemotherapy: a cross- sectional study," $B M C$ Complementary \& Alternative Medicine, vol. 13, article 16, 2013.

[40] GVR, "Alternative and complementary medicine market analysis by intervention (botanicals, acupuncture, mind, body, and yoga, magnetic intervention), by distribution method, and segment forecasts, 2013 - 2025," Tech. Rep., 2017.

[41] M. Alameddine, F. Naja, S. Abdel-Salam, S. Maalouf, and C. Matta, "Stakeholders' perspectives on the regulation and integration of complementary and alternative medicine products in Lebanon: a qualitative study," BMC Complementary and Alternative Medicine, vol. 11, article 71, 2011.

[42] M. Wells, L. Sarna, M. E. Cooley et al., "Use of complementary and alternative medicine therapies to control symptoms in women living with lung cancer," Cancer Nursing, vol. 30, no. 1, pp. 45-55, 2007.

[43] J. Bauml, C. J. Langer, T. Evans, S. N. Garland, K. Desai, and J. J. Mao, "Does perceived control predict Complementary and Alternative Medicine (CAM) use among patients with lung cancer? A cross-sectional survey," Supportive Care in Cancer, vol. 22, no. 9, pp. 2465-2472, 2014.

[44] H.-Y. Chang, M. Wallis, and E. Tiralongo, "Use of complementary and alternative medicine among people living with diabetes: literature review," Journal of Advanced Nursing, vol. 58, no. 4, pp. 307-319, 2007.

[45] F. Naja, R. A. Fadel, M. Alameddine et al., "Complementary and alternative medicine use and its association with quality of life among Lebanese breast cancer patients: a cross-sectional study," BMC Complementary and Alternative Medicine, vol. 15, article 444, 2015.

[46] F. Naja, M. Alameddine, L. Itani, H. Shoaib, D. Hariri, and S. Talhouk, "The use of complementary and alternative medicine among lebanese adults: results from a national survey," Evidence-based Complementary and Alternative Medicine, vol. 2015, Article ID 682397, 9 pages, 2015.

[47] S. M. Ching, Z. A. Zakaria, F. Paimin, and M. Jalalian, "Complementary alternative medicine use among patients with type 2 diabetes mellitus in the primary care setting: a crosssectional study in Malaysia," BMC Complementary and Alternative Medicine, vol. 13, article 148, 2013.

[48] S. S. Hasan, S. I. Ahmed, N. I. Bukhari, and W. C. W. Loon, "Use of complementary and alternative medicine among patients with chronic diseases at outpatient clinics," Complementary Therapies in Clinical Practice, vol. 15, no. 3, pp. 152-157, 2009.

[49] A. Wanchai, J. M. Armer, and B. R. Stewart, "Complementary and alternative medicine use among women with breast cancer: 
a systematic review," Clinical Journal of Oncology Nursing, vol. 14, no. 4, pp. E45-E55, 2010.

[50] THE WORLD BANK, "World Bank national accounts data, and OECD National Accounts data files," 2017, http://data .worldbank.org/indicator/NY.GDP.PCAP.CD.

[51] B. Saad, H. Azaizeh, G. Abu-Hijleh, and O. Said, "Safety of traditional Arab herbal medicine," Evidence-Based Complementary and Alternative Medicine, vol. 3, no. 4, pp. 433-439, 2006.

[52] S. M. Salah and A. K. Jäger, "Screening of traditionally used Lebanese herbs for neurological activities," Journal of Ethnopharmacology, vol. 97, no. 1, pp. 145-149, 2005.

[53] N. R. Slifman, W. R. Obermeyer, B. K. Aloi et al., "Contamination of botanical dietary supplements by Digitalis lanata," New England Journal of Medicine, vol. 339, no. 12, pp. 806-811, 1998.

[54] B. Cheng, C. T. Hung, and W. Chiu, "Herbal medicine and anaesthesia," Hong Kong Medical Journal, vol. 8, no. 2, pp. 123130, 2002.

[55] I. A. Malik and S. Gopalan, "Use of CAM results in delay in seeking medical advice for breast cancer," European Journal of Epidemiology, vol. 18, no. 8, pp. 817-822, 2003.

[56] R. Sobel, "Science and nescience: the issue of alternative medicine," Public Health Reviews, vol. 27, no. 4, pp. 247-260, 1999.

[57] D. J. Hufford, "Evaluating complementary and alternative medicine: the limits of science and of scientists," Journal of Law, Medicine and Ethics, vol. 31, no. 2, pp. 198-212, 2003.

[58] E. H. Morreim, "A dose of our own medicine: alternative medicine, conventional medicine, and the standards of science," Journal of Law, Medicine and Ethics, vol. 31, no. 2, pp. 222-235, 2003.

[59] J. A. Pagán and A. Puig, "Differences in access to health care services between insured and uninsured adults with diabetes in Mexico," Diabetes Care, vol. 28, no. 2, pp. 425-426, 2005.

[60] T. J. Kaptchuk, "The placebo effect in alternative medicine: can the performance of a healing ritual have clinical significance?" Annals of Internal Medicine, vol. 136, no. 11, pp. 817-825, 2002.

[61] M. J. Verhoef, "Declining conventional cancer treatment and using Complementary and Alternative Medicine: a problem or a challenge?" Current Oncology, vol. 15, no. 0, 2008.

[62] J. Abou-Rizk, M. Alameddine, and F. Naja, "Prevalence and characteristics of cam use among people living with hiv and aids in lebanon: implications for patient care," Evidence-Based Complementary and Alternative Medicine, vol. 2016, pp. 1-11, 2016.

[63] F. Naja, M. Alameddine, M. Abboud, D. Bustami, and R. Al Halaby, "Complementary and alternative medicine use among pediatric patients with leukemia: the case of Lebanon," Integrative Cancer Therapies, vol. 10, no. 1, pp. 38-46, 2011.

[64] E. L. Davis, B. Oh, P. N. Butow, B. A. Mullan, and S. Clarke, "Cancer patient disclosure and patient-doctor communication of complementary and alternative medicine use: a systematic review," Oncologist, vol. 17, no. 11, pp. 1475-1481, 2012.

[65] K. B. Wright, L. Sparks, and H. D. O'hair, Health communication in the 21st century, John Wiley Sons, 2012.

[66] J. Ge, J. Fishman, and N. Vapiwala, "Patient-physician communication about complementary and alternative medicine in a radiation oncology setting," International Journal of Radiation Oncology, Biology, Physics, vol. 85, no. 1, pp. e1-e6, 2013.

[67] K. Bjerså, E. Stener Victorin, and M. Fagevik Olsén, "Knowledge about complementary, alternative and integrative medicine (CAM) among registered health care providers in Swedish surgical care: a national survey among university hospitals," BMC Complementary and Alternative Medicine, vol. 12, article no. $42,2012$.

[68] L. C. Winslow and H. Shapiro, "Physicians want education about complementary and alternative medicine to enhance communication with their patients," Archives of Internal Medicine, vol. 162, no. 10, pp. 1176-1181, 2002.

[69] A. Bowling, "Mode of questionnaire administration can have serious effects on data quality," Journal of Public Health, vol. 27, no. 3, pp. 281-291, 2005. 


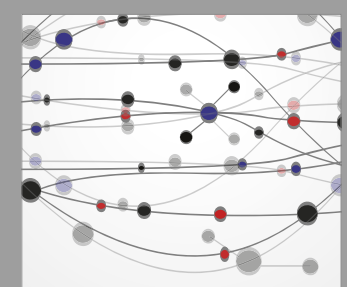

The Scientific World Journal
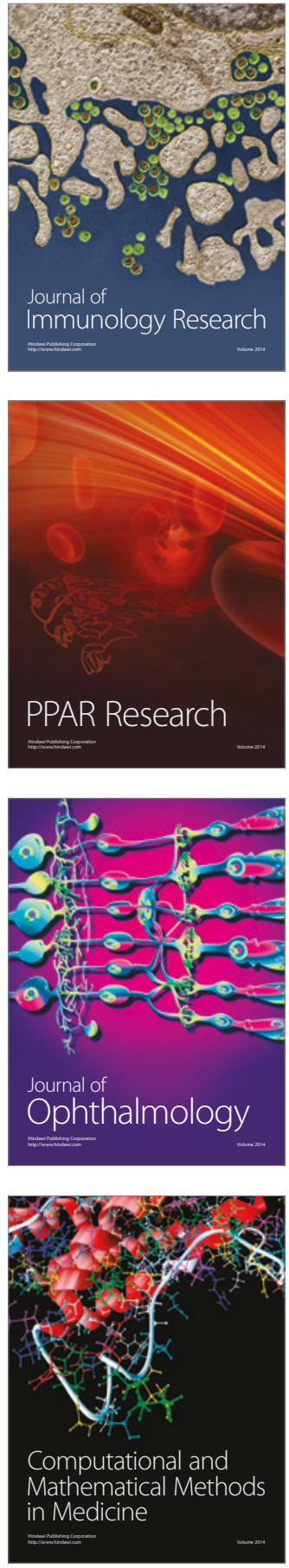

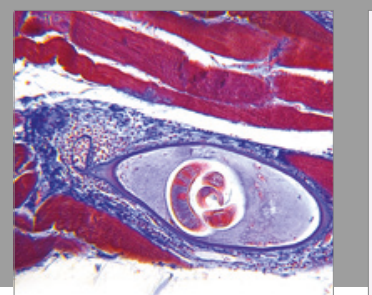

Gastroenterology Research and Practice
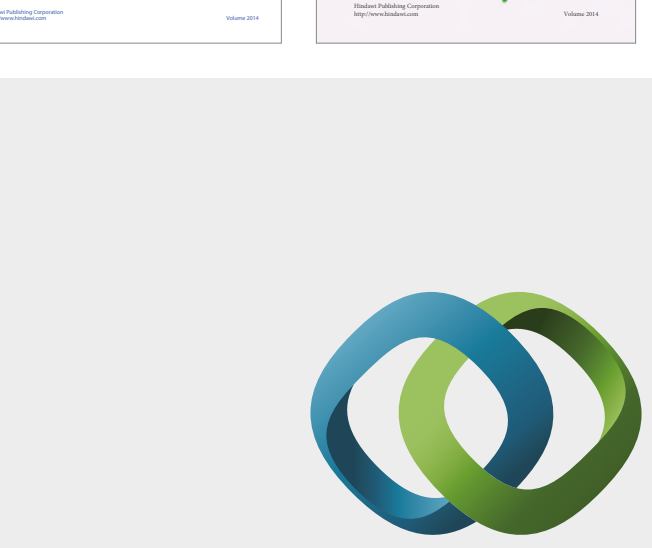

\section{Hindawi}

Submit your manuscripts at

https://www.hindawi.com
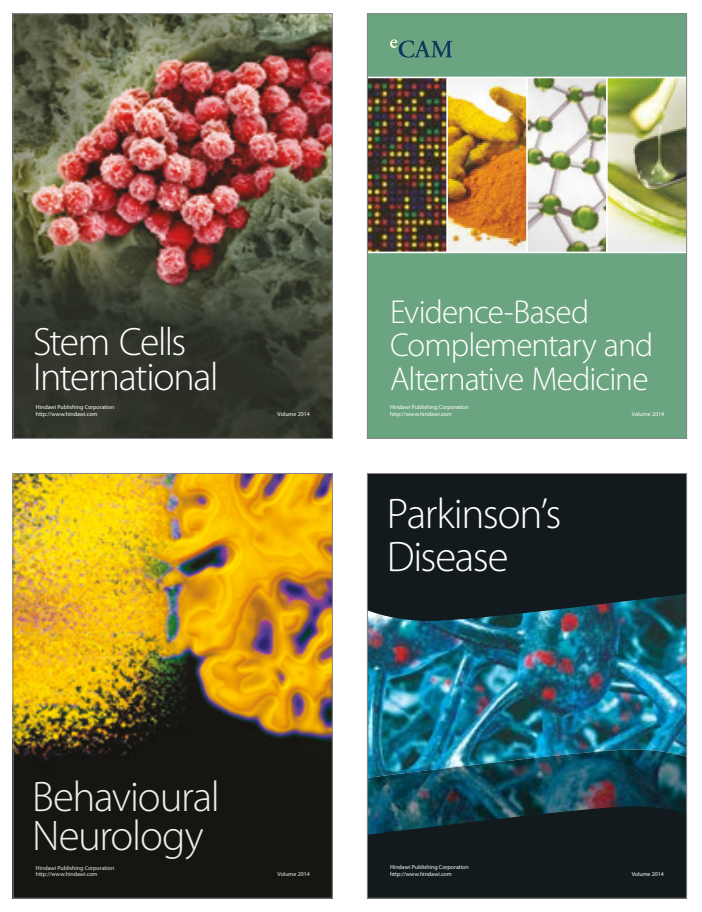
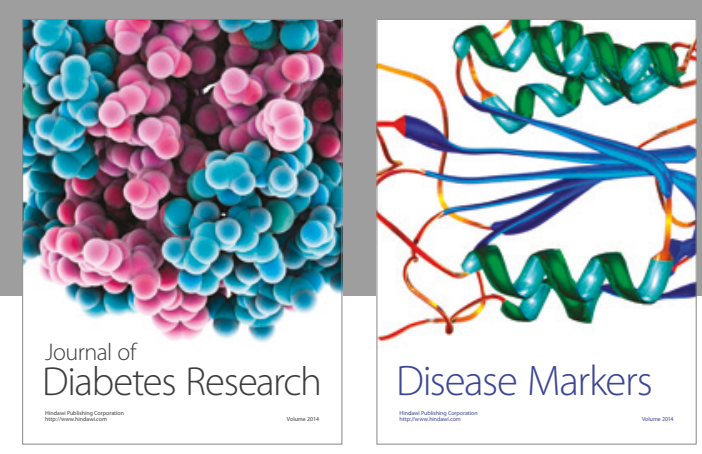

Disease Markers
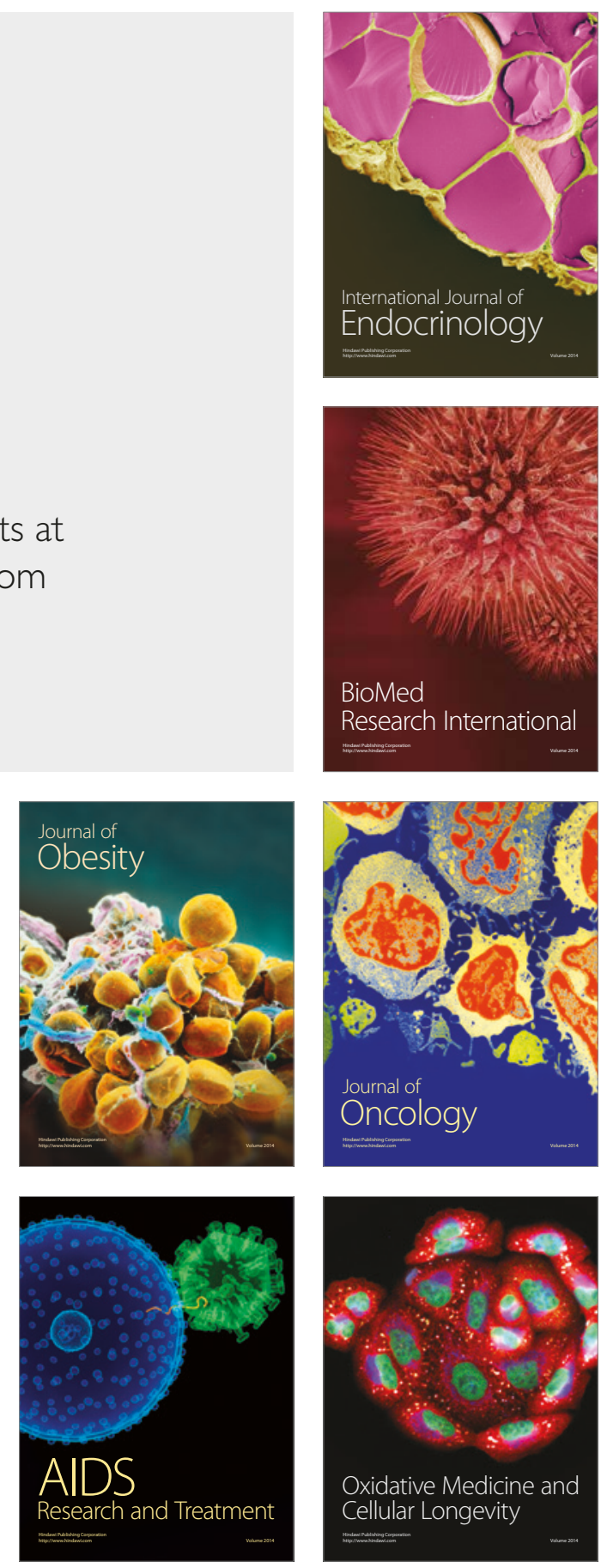